Funding: Alcohol Education and Research Council (grant No R17/97).

Competing interests: None declared.

1 English DR, Holman CDJ, Milne E, Winter MG, Hulse GK, Codde JP, et al. The quantification of drug caused morbidity and mortality in Australia 1995. Canberra: Commonwealth Department of Human Services and Health, 1995.

2 Anderson P, Cremona A, Paton A, Turner C, Wallace P. The risk of alcohol. Addiction 1993;88:1493-1508.

3 Marmot M, Brunner E. Alcohol and cardiovascular disease: the status of the U shaped curve. BMJ 1991:303:565-8.

4 Maclure M. Demonstration of deductive meta-analysis: ethanol intake and risk of myocardial infarction. Epidemiol Rev 1993;15:328-51.

Klatsky AL. Epidemiology of coronary heart disease-influence of alcohol. Alcohol Clin Exp Res 1994;18:88-96.

6 Chick J. Alcohol, health, and the heart: implications for clinicians. Alcohol Alcohol 1998;33:576-91.

7 Beaglehole R, Jackson R. Alcohol, cardiovascular diseases and all causes of death: a review of the epidemiological evidence. Drug Alcohol Rev 1992:2:275-90.

8 Poikolainen K. Alcohol and mortality: a review. J Clin Epidemiol 1995;48:455-65

9 Rehm J, Bondy S. Alcohol and all-cause mortality: an overview. In: Novartis Foundation Symposium, ed. Alcohol and cardiovascular diseases. Chichester: Wiley, 1998.

10 Roval Colleges of Physicians, Psychiatrists, and General Practitioners. Alcohol and the heart in perspective: sensible limits reaffirmed. London: Royal Colleges, 1995.

11 Inter-Departmental Working Group. Sensible drinking. London: Department of Health, 1995.

12 Holman CDJ, Armstrong BK. The quantification of alcohol-caused morbidity and mortality in Australia: the authors respond. Med J Aust 1992;157:560-1
13 Holman CDJ, Armstrong BK, Arias LN, Martin CA, Hatton WM, Hayward LD, et al. The quantification of drug caused morbidity and mortality in Australia (appendix 1). Canberra: Commonwealth Department of Community Services and Health, 1988.

14 Corrao G, Bagnardi V, Zambon A, Arico S. Exploring the dose-response relationship between alcohol consumption and the risk of several alcohol-related conditions: a meta-analysis. Addiction 1999;94:1551-73.

15 Corrao G, Rubbiata L, Bagnardi V, Zambon A, Poikolainen K. Alcohol and coronary heart disease: a meta-analysis. Addiction 2000;95:1505-23.

16 White IR. The level of alcohol consumption at which all-cause mortality is least. J Clin Epidemiol 1999;52:967-75.

17 Office for National Statistics, Social Survey Division. General household survey, 1996-1997 (computer file SN 3804), 2nd edn. Colchester, Essex: Data Archive [distributor], 5 Oct 1998.

18 Office for National Statistics. Twentieth century mortality: 95 years of mortality data in England and Wales by age, sex,year and underlying cause. [CD ROM and 1997 Update disk]. London: ONS, 1997.

19 White IR, Nanchahal K. The number of deaths and person-years of life lost attributable to alcohol consumption in England and Wales in 1995. London: London School of Hygiene and Tropical Medicine, 1997. [Technical report.]

20 Murray JL, Lopez AD, eds. The global burden of disease: a comprehensive assessment of mortality and disability from diseases, injuries and risk factors in 1990 and projected to 2020. Cambridge, MS: Harvard University Press, 1996.

21 White IR, Altmann DR, Nanchahal K. 'Optimal'levels of alcohol consumption for men and women at different ages, and the all-cause mortality attributable to drinking. London: London School of Hygiene and Tropical Medicine, 2000. [Technical report.]

22 Britton A, McPherson K. Mortality in England and Wales attributable to current alcohol consumption. J Epidemiol Community Health 2001;55:383-8.

(Accepted 12 February 2002)

\title{
Analysis of predicted coronary heart disease risk in England based on Framingham study risk appraisal models published in 1991 and 2000
}

\author{
Kiran Nanchahal, John R Duncan, Paul N Durrington, Rodney T Jackson
}

Health Promotion

Research Unit,

Department of

Public Health and

Policy, London

School of Hygiene

and Tropical

Medicine, London

WC1E 7HT

Kiran Nanchahal

lecturer in medical

statistics

GlaxoSmithKline,

New Frontiers

Science Park, Third

Avenue, Harlow

CM19 5AW

John R Duncan

statistician

Clinical Research

Division II,

University Medical

Unit, Manchester

Royal Infirmary,

Manchester

M13 9WL

Paul N Durrington

professor of medicine

continued over

BMJ 2002;325:194-5
In 2000 the UK government launched the national service framework for coronary heart disease, setting national standards for improving prevention, diagnosis, and treatment. In agreement with recent recommendations on preventing coronary heart disease ${ }^{1}$ and managing hypertension, ${ }^{2}$ this programme includes use of coronary risk appraisal models from the Framingham study published in $1991^{3}$ to help identify patients eligible for drug treatment. These models were updated in 2000, ${ }^{4}$ incorporating further follow up and additional risk factors. We compare the predicted risks calculated using the two models and assess the implications for preventing heart disease.

\section{Methods and results}

The health survey for England is an annual, nationwide, household based, cross sectional survey of a representative sample of the population. We used the 1998 survey data for 5518 (62.3\% of 8852) participants aged 35-74 with complete information on factors needed for assessment of coronary disease risk, after exclusion of $738(7.7 \%$ of 9590) participants reporting angina, heart attack, or stroke diagnosed by a doctor. ${ }^{5}$ The 2000 models allow calculation of risk over a period of four years, ${ }^{4}$ whereas the 1991 models permit estimation of risk over 4-12 years. ${ }^{3}$ We estimated the 10 year and four year probabilities of developing heart disease predicted using the 1991 equations and the four year risk predicted using the 2000 equations.

Summary statistics for four year coronary disease risk per 100 population based on the 1991 and 2000 models within a range of risk categories show that both models generally produce similar distributions (table). Although substantial statistical agreement exists between classification of participants into risk categories based on the two models, participants within each category based on the 1991 models were distributed across a wide range of risk categories based on the 2000 models.

\section{Comment}

Although population distributions of coronary risk calculated with the two models are generally similar, a significant number of people meeting criteria for drug treatment on the basis of the 1991 models would not meet the equivalent criteria on the basis of the 2000 models. Current UK guidelines generally recommend offering drug treatment for hypertension or hypercholesterolaemia to patients with a 10 year risk $\geqslant 15 \% .^{1{ }^{2}}$ We used a $5 \%$ risk of a coronary event in four years as being equivalent to a 10 year risk of $15 \%$, rather than $6 \%$ over four years, because risk increases exponentially rather than linearly with age. Had we used $6 \%$, the discrepancy between the 1991 and 2000 models would have been even greater. 
Number of participants and mean (SD) risk in four year predicted risk categories based on coronary heart disease risk appraisal models from the Framingham study published in $1991^{3}$ and $2000^{4}$

\begin{tabular}{|c|c|c|c|c|c|c|c|c|c|c|}
\hline \multicolumn{2}{|c|}{1991 models } & \multicolumn{9}{|c|}{2000 models: risk category* } \\
\hline $\begin{array}{l}\text { Risk } \\
\text { category* }\end{array}$ & Mean (SD) & $<2$ & $\geqslant 2,<4$ & $\geqslant 4,<5$ & $\geqslant 5,<6$ & $\geqslant 6,<8$ & $\geqslant 8,<10$ & $\geqslant 10$ & All & $\%$ \\
\hline \multicolumn{11}{|l|}{ Men } \\
\hline Mean (SD) & $\mathrm{N} / \mathrm{A}$ & $1.2(0.43)$ & $2.9(0.58)$ & $4.5(0.29)$ & $5.5(0.30)$ & $6.9(0.55)$ & $8.9(0.58)$ & $15.8(6.57)$ & $4.4(4.53)$ & $\mathrm{N} / \mathrm{A}$ \\
\hline$<2$ & $1.0(0.52)$ & 812 & 61 & 0 & 0 & 0 & 0 & 0 & 873 & 34.0 \\
\hline$\geqslant 2,<4$ & $3.0(0.58)$ & 74 & 504 & 21 & 1 & 0 & 0 & 0 & 600 & 23.3 \\
\hline$\geqslant 4,<5$ & $4.5(0.29)$ & 0 & 118 & 57 & 12 & 5 & 0 & 0 & 192 & 7.5 \\
\hline$\geqslant 5,<6$ & $5.5(0.29)$ & 0 & 53 & 76 & 53 & 15 & 0 & 0 & 197 & 7.7 \\
\hline$\geqslant 6,<8$ & $6.9(0.56)$ & 0 & 0 & 53 & 77 & 89 & 20 & 2 & 241 & 9.4 \\
\hline$\geqslant 8,<10$ & $9.0(0.55)$ & 0 & 0 & 0 & 14 & 108 & 41 & 14 & 177 & 6.9 \\
\hline$\geqslant 10$ & $13.9(3.86)$ & 0 & 0 & 0 & 0 & 21 & 70 & 200 & 291 & 11.3 \\
\hline All & $4.6(4.31)$ & 886 & 736 & 207 & 157 & 238 & 131 & 216 & 2571 & 100 \\
\hline$\%$ & $\mathrm{~N} / \mathrm{A}$ & 34.5 & 28.6 & 8.0 & 6.1 & 9.3 & 5.1 & 8.4 & 100 & $\mathrm{~N} / \mathrm{A}$ \\
\hline \multicolumn{11}{|l|}{ Women } \\
\hline Mean (SD) & $\mathrm{N} / \mathrm{A}$ & $0.8(0.53)$ & $2.8(0.57)$ & $4.5(0.27)$ & $5.5(0.30)$ & $6.8(0.57)$ & $8.9(0.51)$ & $13.9(2.81)$ & $1.8(2.01)$ & $\mathrm{N} / \mathrm{A}$ \\
\hline$<2$ & $0.7(0.56)$ & 1831 & 125 & 4 & 2 & 2 & 0 & 0 & 1964 & 66.6 \\
\hline$\geqslant 2,<4$ & $2.8(0.56)$ & 228 & 294 & 34 & 10 & 3 & 0 & 0 & 569 & 19.3 \\
\hline$\geqslant 4,<5$ & $4.5(0.28)$ & 9 & 102 & 27 & 12 & 7 & 0 & 1 & 158 & 5.4 \\
\hline$\geqslant 5,<6$ & $5.4(0.29)$ & 2 & 37 & 17 & 13 & 4 & 1 & 0 & 74 & 2.5 \\
\hline$\geqslant 6,<8$ & $6.8(0.56)$ & 1 & 17 & 29 & 23 & 27 & 6 & 2 & 105 & 3.6 \\
\hline$\geqslant 8,<10$ & $8.8(0.60)$ & 0 & 1 & 6 & 7 & 9 & 9 & 6 & 38 & 1.3 \\
\hline$\geqslant 10$ & $12.3(1.92)$ & 0 & 1 & 0 & 3 & 9 & 10 & 16 & 39 & 1.3 \\
\hline All & $1.9(2.25)$ & 2071 & 577 & 117 & 70 & 61 & 26 & 25 & 2947 & 100 \\
\hline$\%$ & $\mathrm{~N} / \mathrm{A}$ & 70.3 & 19.6 & 4.0 & 2.4 & 2.1 & 0.9 & 0.8 & 100 & $\mathrm{~N} / \mathrm{A}$ \\
\hline
\end{tabular}

Weighted $x(95 \% \mathrm{Cl})$ : men 0.83 (0.82 to 0.84$)$; women 0.67 (0.65 to 0.69$)$. N/A=not applicable. *Number of coronary heart disease events per 100 population.

Our study confirms that risk of coronary disease in Britain is high. On the basis of the 1991 risk appraisal models, approximately $32 \%$ of men and $7 \%$ of women aged $35-74$ in England are at $\geqslant 15 \%$ risk of developing heart disease in the next 10 years. The 2000 models give figures for a four year risk $\geqslant 5 \%$ of $29 \%$ for men and $6 \%$ for women. Although only $1-2 \%$ of men and women ineligible for drug treatment under current criteria would be eligible if the 2000 models were used, $20 \%$ of men and $43 \%$ of women currently recommended drug treatment would not be eligible if their four year risk based on the updated models was used. Sensitivity and specificity for the 1991 risk appraisal models would be $97.6 \%$ and $90.0 \%$ for men and $79.7 \%$ and $96.0 \%$ for women, considering the updated models to provide the most up to date assessment of coronary disease risk for asymptomatic men and women. Although thresholds for drug treatment are somewhat arbitrary and depend to a large degree on the resources available, we recommend that these findings are taken into account when guidelines for coronary heart disease prevention are updated in accordance with emerging scientific evidence for statin treatment and management of mild hypertension.

We thank J N Morris for comments on an earlier draft of the manuscript.

Contributors: $\mathrm{KN}$ devised this study and drafted the manuscript of the paper, JD undertook the statistical analyses, and all authors contributed to writing the paper. $\mathrm{KN}$ will act as guarantor.

JD received a SmithKline Beecham scholarship while an MSc student at the London School of Hygiene and Tropical Medicine when some of this work was done.

Competing interests: None declared.

1 British Cardiac Society, British Hyperlipidaemia Association, British Hypertension Society, British Diabetic Association. Joint British recommendations on prevention of coronary heart disease in clinical practice. Heart 1998;80:S1-29.
2 Ramsay LE, Williams B, Johnston DG, MacGregor GA, Poston L, Potter $\mathrm{JF}$, et al. British Hypertension Society guidelines for hypertension $\mathrm{JF}$, et al. British Hypertension Society guidelin
management 1999: summary. BMJ 1999;319:630-5.

3 Anderson KM, Wilson PWF, Odell PM, Kannel WB. An updated coronary risk factor profile: a statement for health professionals. Circula tion 1991;83:356-62.

4 D'Agostino RB, Russell MW, Huse DM, Ellison C, Silbershatz H, Wilson PW, et al. Primary and subsequent coronary risk appraisal: new results from the Framingham study. Am Heart J 2000;139:272-81.

5 Erens B, Primatesta P. Health survey for England, 1998 [computer file]. 2nd ed. Colchester, Essex: The Data Archive [distributor], 2000. [SN: 4150.] (Accepted 13 March 2002)

\section{Corrections and clarifications}

Minerva

A keyboard slip seems to have accounted for Minerva attributing a study to a US rather than UK hospital (20 April, p 986). The study was about physical illness in patients referred to psychiatric clinics and was reported in Acta Psychiatrica Scandinavica.

Science, medicine, and the future: New vaccine development

Because of an editorial oversight (mistaking one competing interest form for another), this article by Gregory A Poland and colleagues (1 June, pp 1315-9) did not include Dr Poland's declaration that he had performed a trial of a DNA vaccine funded by Powderject Vaccines.

Unexplained differences in sex ratios at birth in Europe and North America

In the table accompanying this Research Pointer by Victor Grech and colleagues (27 April, pp 1010-1), readers may have been surprised to see that Denmark and Finland seemed to have exactly the same numbers of female and total live births. This was in fact an error, which arose during editing and was not picked up on the proofs. The figures for Finland were correct, but for Denmark the number of female live births are 1588490 and total live births 3269412.
Faculty of Medical and Health Sciences, University of Auckland, Grafton Mews, 52-54 Grafton Road, Auckland, New Zealand Rodney T Jackson professor of epidemiology

Correspondence to: Kiran Nanchahal kiran.nanchahal@ lshtm.ac.uk 